\title{
Combined Effects of Temperature and Salinity on the Growth and Pulsation of Moon Jellyfish (Aurelia coerulea) Ephyrae
}

\author{
Zhilu Fu ${ }^{1,2, *}$, Jie Li ${ }^{3,4}$, Jiale Wang ${ }^{3,4}$, Junxiang Lai ${ }^{3}$, Yin Liu ${ }^{5,6}$, Ming Sun ${ }^{5,7,8, *}$ \\ ${ }^{1}$ Key Laboratory of Protection and Utilization of Marine Resources, Guangxi University for Nationalities, Nanning, China \\ ${ }^{2}$ Guangxi Key Laboratory of Utilization of Microbial and Botanical Resources, Guangxi University for Nationalities, Nanning, China \\ ${ }^{3}$ Guangxi Key Laboratory of Marine Environmental Science, Guangxi Beibu Gulf Marine Research Center, Guangxi Academy of Sciences, \\ Nanning, China \\ ${ }^{4}$ School of Marine Science, Guangxi University, Nanning, China \\ ${ }^{5}$ Liaoning Province Key Laboratory of Marine Biological Resources and Ecology, Liaoning Ocean and Fisheries Science Research Institute, \\ Dalian, China \\ ${ }^{6}$ College of Fisheries and Life Science, Dalian Ocean University, Dalian, China \\ ${ }^{7}$ Key Laboratory of Experimental Marine Biology, Institute of Oceanology, Chinese Academy of Sciences, Qingdao, China \\ ${ }^{8}$ University of Chinese Academy of Sciences, Beijing, China
}

Email address:

fzl19@163.com(Zhilu Fu), sunming0408@163.com(Ming Sun)

${ }^{*}$ Corresponding author

\section{To cite this article:}

Zhilu Fu, Jie Li, Jiale Wang, Junxiang Lai, Yin Liu, Ming Sun. Combined Effects of Temperature and Salinity on the Growth and Pulsation of Moon Jellyfish (Aurelia coerulea) Ephyrae. American Journal of Life Sciences. Vol. 8, No. 5, 2020, pp. 144-151.

doi: 10.11648/j.ajls.20200805.19

Received: August 8, 2020; Accepted: August 20, 2020; Published: September 14, 2020

\begin{abstract}
Blooms of the scyphozoan jellyfish Aurelia coerulea have caused serious problems for the fishing industry and the power plants in the coastal waters of China. The population size of adult medusae is strongly influenced by their ability to survive the ephyra stage. In this study, the growth and pulsation of $A$. coerulea ephyrae from the northern Yellow Sea were analyzed under sixteen different temperature $\left(10,15,20\right.$, and $\left.25^{\circ} \mathrm{C}\right)$ and salinity $(22,25,28$ and $31 \mathrm{PSU})$ combinations over a 21 -day experimental period. The temperature had a significant effect on the growth of ephyrae. The growth rate of ephyrae increased with increasing temperature. The effects of salinity and its interaction with temperature on the growth of ephyrae were not significant. The highest growth rate was recorded in the $25^{\circ} \mathrm{C}$ and 25 PSU group. The pulsation rate of ephyrae was also significantly influenced by temperature. The mean pulsation rates of newly released ephyrae were 24.2, 39.1, 52.5, and 73.15 beats $\min ^{-1}$ at $10,15,20$, and $25^{\circ} \mathrm{C}$, respectively. As ephyrae developed into medusae, the pulsation rates generally decreased. Salinity and its interaction with temperature did not have a significant effect on the pulsation of ephyrae. We conclude that a warm spring can cause an $A$. coerulea bloom in that year.
\end{abstract}

Keywords: Aurelia coerulea, Ephyrae, Growth, Pulsation, Temperature, Salinity

\section{Introduction}

Mass blooms of large jellyfish (Scyphozoa) have become increasingly common in oceans in many parts of the world, causing significant environmental and economic impacts. Jellyfish blooms can have considerable impacts on marine ecosystems since jellyfish compete for food with zooplanktivorous fishes and predate directly on fish larvae and eggs $[1,2]$. Hence, increases in jellyfish populations may lead to depletion of fish stocks and reductions in harvests [3-5]. In addition, dense aggregations of medusae can also cause serious problems for fisheries by clogging fishing gear and coastal power plants by blocking cooling water systems [6-8]. Therefore, it is important not only to clarify the mechanisms 
of jellyfish population blooms but also to forecast future outbreaks and determine appropriate countermeasures.

The Aurelia spp. (class: Scyphozoa), commonly known as the moon jellyfish, is abundantly found in many temperate regions. It has been reported that genus Aurelia has at least 12 cryptic species, and the species found in China were previously recognized as Aurelia sp. 1 and recently changed to Aurelia coerulea [6]. In China, A. coerulea is one of the most common bloom-forming species. These species are mainly found across the shallow coastal waters of the Yellow Sea and the Bohai Sea, including Shandong, Liaoning, and Hebei provinces $[7,9]$. In recent years, the local fishing industry and the coastal power plants have been negatively impacted by $A$. coerulea blooms, even causing power plant shutdown in severe cases [7, 9]. In 2007, a massive $A$. coerulea bloom was observed along the coastal waters of Shandong Province (Weihai city and Yantai city) between the months of June and September [10, 11]. In 2008, the intake screens of power plants in Qinhuangdao city and Weihai city were unclogged by removing more than 4000 tons wet weight and 20-50 tons of $A$ coerulea medusae, respectively [7]. Similarly, in 2009, more than 10 tons of medusae were removed from the intake screens of a power plant in Qingdao city, Shandong Province [7].

The recent increase in A. coerulea blooms in China may not be attributed to decadal climate change, which affects temporal variations in jellyfish biomass in the Bering Sea, but to environmental changes caused by human activities. Many previous studies have speculated the causes of jellyfish blooms include decreased fish stocks due to overfishing, increased zooplankton predation causing eutrophication, increased ocean water temperatures due to global warming, and increased numbers of polyp attachment sites due to marine construction. However, it is very difficult to specify which factors are primarily responsible since blooms may be caused by the interactions of multiple factors $[4,7,12,13]$.

The life cycle of $A$. coerulea alternates between a benthic polyp stage and a pelagic medusa stage. Their survival of the ephyra stage acts as a determining factor that impacts the population of adult medusae. Hence, it is necessary to investigate population dynamics during the ephyra stage to understand the causes of medusa blooms. Little information exists regarding the physio-ecology of the ephyrae of genus Aurelia. Previous studies have demonstrated that the growth of ephyrae of genus Aurelia can be affected by several environmental factors such as temperature, food and salinities [14-17]. Among these environmental factors, temperature had the greatest impact on growth ephyrae. Båmstedt et al. [14] studied the growth rate of $A$. aurita ephyrae at different temperatures and salinities and found a 5.4 times higher growth rate at $18^{\circ} \mathrm{C}$ than at $6^{\circ} \mathrm{C}$. Another study analyzed the growth rate of $A$. labiata ephyrae between $8-28^{\circ} \mathrm{C}$ and found an initial increase till $21^{\circ} \mathrm{C}$, followed by a gradual decrease [15]. For the pulsation rate of $A$. aurita, Dillon [18] found a significantly higher pulsation rate of $A$. aurita ephyrae at $20^{\circ} \mathrm{C}$ compared with $10^{\circ} \mathrm{C}$; however, lower values were observed between 25 and $35^{\circ} \mathrm{C}$. These results were consistent with a previous study where higher pulsation rates were observed for
A. aurita ephyrae between 11 and $25^{\circ} \mathrm{C}$, but the values decreased at temperatures $>25^{\circ} \mathrm{C}$ [19]. The effect of salinity on the growth of $A$. aurita ephyrae did not show a clear trend [14]. Reduced salinity was associated with an acute effect of an increased pulsation rate, but this effect disappeared within 2 days [18]. Additionally, the impact of other parameters on the survival in the ephyra stage has not been evaluated. There are no published reports on the combined effects of temperature and salinity on growth and pulsation in this species.

In the coastal waters of northern China, $A$. coerulea ephyrae follow a season-specific appearance pattern, mainly in the middle or late spring $[9,16]$. Large variations in recruitment are reflected in the population size of adult medusae. This variation is dependent upon the irregular mortality and growth rate in the ephyra stage. Since salinity and temperature might significantly impact the growth and locomotion of $A$. coerulea ephyrae in the northern Yellow Sea in China; thus, experimental investigations were performed to examine the combined effects of temperature and salinity on the growth and pulsation of $A$. coerulea ephyrae.

\section{Materials and Methods}

\subsection{Ephyrae Preparation}

Ephyrae of $A$. coerulea were obtained from stock cultures of polyps; they were originally derived from matured medusae obtained from the Heishijiao area, Dalian (northern Yellow Sea), China. Planulae of $A$. coerulea were placed in opaque plastic boxes containing approximately $20 \mathrm{~L}$ of filtered seawater with a salinity of 31 PSU. The planulae were incubated and allowed to settle on $0.5 \mathrm{~mm}$ thick opaque corrugated plates $(40 \times 35 \mathrm{~cm}$ in size $)$ at $20-25^{\circ} \mathrm{C}$. Post-transformation into the polyp stage, they ate Artemia spp. nauplii ad libitum once or twice weekly, and a seawater alternative. Finally, strobilation was induced at $15^{\circ} \mathrm{C}$ to release the ephyrae.

\subsection{Experimental Design}

A two-factor orthogonal design was used to determine the effect of temperature $\left(10,15,20\right.$, and $\left.25^{\circ} \mathrm{C}\right)$ and salinity (22, 25,28 , and $31 \mathrm{PSU}$ ) on the growth of $A$. coerulea ephyrae over a 21-day period. The four temperature levels span the temperature range from mid-spring to summer in the northern Yellow Sea, that is, the period from the release of ephyrae to development into adult medusae. The salinity levels represent the salinity range from the estuary to offshore waters in the northern Yellow Sea, where $A$. coerulea is naturally distributed. All further experiments were performed using ephyrae that released from their strobilae within $48 \mathrm{~h}$. Ten ephyrae were arbitrarily placed in a 1 L glass beaker containing $0.45 \mu \mathrm{m}$ of filtered seawater. In this study, $1-\mathrm{L}$ glass beakers containing 10 ephyrae each were randomly allocated to 16 temperature and salinity groups, with one beaker assigned to each combination.

For the 10 and $15^{\circ} \mathrm{C}$ treatments, the beakers with ephyrae 
were placed in incubators to maintain constant temperatures. For the $20^{\circ} \mathrm{C}$ treatment, the beakers were placed in a room that was kept at a constant $20^{\circ} \mathrm{C}$. For the $25^{\circ} \mathrm{C}$ treatment, the beakers were submerged in water baths held at $25^{\circ} \mathrm{C}$. Temperatures at each treatment were checked with thermometers twice per day to ensure a constant water temperature constant $\left( \pm 0.2^{\circ} \mathrm{C}\right)$. Additionally, experimental seawater samples with different salinities were prepared by adding purified water to filtered seawater.

Ephyrae were held at their treatment temperatures and transferred to their respective salinity conditions to acclimate to the experimental conditions for $24 \mathrm{~h}$. After $24 \mathrm{~h}$ of acclimation, the ephyrae were fed adequate Artemia nauplii twice daily (approximately $300-1000$ prey $\mathrm{L}^{-1}$ ). The protocol was designed to maximize the growth rate that would generate a significant difference between the treatments. Post-feeding, the unfinished food was replaced with filtered seawater at identical salinity and temperature. The seawater used for replacement was placed in the corresponding incubator or room 1 day before use to reach the experimental temperature.

During the experiment, continuous observations of the survival, morphological changes, and food digestion of ephyrae were recorded in detail. At each 3-d interval, the bell diameter size of all ephyrae was measured. The bell diameter in this study was defined as the distance between two opposite lappet tips. A wide-mouthed pipette was used to place the ephyrae $(<10 \mathrm{~mm})$ on a glass dish, allowed to relax, followed by measurement using a dissecting microscope and a grid with 0.01-mm gradations; ephyrae larger than $10 \mathrm{~mm}$ were individually placed on a small glass container, allowed to relax and then measured using a ruler with 1-mm gradations. Each measurement was completed within $1 \mathrm{~min}$. After the measurement, beakers with ephyrae were quickly placed back under experimental conditions. The following equation was used to estimate the growth rate [15]:

$$
\text { Growth rate }\left(\% \mathrm{~d}^{-1}\right)=\ln \left[\left(\mathrm{D}_{2} / \mathrm{D}_{1}\right)^{3}\right] /\left(\mathrm{t}_{2}-\mathrm{t}_{1}\right) \times 100
$$

where $D_{1}$ and $D_{2}$ represent the mean diameters from each treatment group in two subsequent analyses, and $t_{1}$ and $t_{2}$ (days) are the experimental days of two consecutive measurements, respectively.

\subsection{Pulsation Rate}

During the 21-d experiment, pulsation rates were also measured in 3-d intervals. Three ephyrae from each beaker were randomly selected for measurement, and each specimen was transferred into a beaker $(1 \mathrm{~L})$ containing seawater at a specific salinity and temperature, followed by counting pulsations using a manual tally counter in 1-min increments for $3 \mathrm{~min}$. Each experiment was repeated thrice, and the mean pulsation rate was derived.

\subsection{Statistics}

Two-way ANOVA was performed after testing for data normality and variance equality (SPSS 26.0) to examine the combined effects of salinity and temperature on the growth and pulsation of ephyrae. Tukey's pairwise comparisons were conducted to compare variables among experimental combinations if the overall results of ANOVA were significant $(\mathrm{p}<0.05)$.

\section{Results}

\subsection{Observations of Feeding and Digestion in Ephyrae Under Different Treatment Conditions}

Feeding and digestion in $A$. coerulea ephyrae under different treatment conditions were observed with the naked eye. The feeding and digestion rates of ephyrae were significantly different under different temperature conditions. At $25^{\circ} \mathrm{C}$, the highest food intake and the shortest digestion time were observed in ephyrae. Five minutes after feeding, Artemia nauplii were ingested in the stomach cavity of ephyrae; this ingestion determined when the color of the stomach cavity turned red. At $1 \mathrm{~h}$ after ingestion, the Artemia nauplii in the stomach cavity of ephyrae were completely digested. As the temperature decreased, the food intake of ephyrae decreased, and digestion slowed accordingly. For example, at $10^{\circ} \mathrm{C}$, digestion in ephyrae was very slow. After 8 $\mathrm{h}$ of ingestion, undigested Artemia nauplii could still be seen in the stomach cavities of ephyrae.

\subsection{Effects of Salinity and Temperature on the Growth of Ephyrae}

At the beginning of the experiment, the mean diameter of $A$. coerulea ephyrae in all treatment groups was $2.52 \pm 0.11 \mathrm{~mm}$, and there was an insignificant difference between different treatment groups $(\mathrm{p}>0.05)$. After 21 days, differences in ephyrae diameters were visible and significant among treatments (Figure 1). The diameter of the ephyrae was largest in the $25^{\circ} \mathrm{C}-25$ PSU treatment group, reaching $27.2 \pm 2.6 \mathrm{~mm}$. Two-way ANOVA showed that temperature significantly influenced the growth of ephyrae $(p<0.01)$; however, salinity $(p>0.05)$ and its combined effect with temperature $(p>0.05)$ did not produce any significant differences.

Figure 2 shows the average growth rates, calculated based on the difference between the initial and final diameter of the ephyrae measured every three days. Warm temperature significantly increased the growth of ephyrae (two-way ANOVA, $\mathrm{p}<0.01)$. The highest growth rate was observed at $25^{\circ} \mathrm{C}$, which resulted in an increase in the diameter of ephyrae from $2.50 \pm 0.16 \mathrm{~mm}$ to $21.8 \pm 4.4 \mathrm{~mm}$ under all salinity conditions at the end of the 21-day experiment. A slower growth rate was observed for ephyrae grown at $10^{\circ} \mathrm{C}$, with an overall growth rate of approximately $6.30-9.51 \%$; they slightly increased from $2.55 \pm 0.09 \mathrm{~mm}$ to $4.60 \pm 0.52 \mathrm{~mm}$ by day 21 . Ephyrae grown at 15 and $18^{\circ} \mathrm{C}$ in all salinities had rapid growth rates at the beginning of the experiment (days 1-6), ranging from $30.41-69.03 \%$, and then the growth rates exhibited a decreasing trend. The overall growth rates ranged from $17.76-30.35 \%$. In addition, some ephyrae in the 15,20 , and $25^{\circ} \mathrm{C}$ treatment groups deformed by everting their bells. The number of deformed ephyrae was lowest in the $15^{\circ} \mathrm{C}$ 
treatment groups and similar among the 20 and $25^{\circ} \mathrm{C}$ treatment groups. The deformed ephyrae showed a reduction in the growth rate in subsequent experiments.

Salinity did not have a significant impact on the growth rate of ephyrae (two-way ANOVA, $\mathrm{p}>0.05$ ). At 15,20 , and $25^{\circ} \mathrm{C}$, the average growth rates of ephyrae were highest in the 25 and 28 PSU treatments, ranging from 20.74-30.24\%. Ephyrae grown in the 22 PSU groups had slightly lower growth rates at these three temperatures, ranging from 20.78-30.88\%. Ephyrae in the 31 PSU grew the slowest, and the overall growth rates at these three temperatures ranged from $17.76-27.85 \%$. However, at $10^{\circ} \mathrm{C}$, the average growth rate of ephyrae was highest in the 31 PSU groups, followed by the 25 PSU groups, the 28 PSU groups, and lowest in the 22 PSU groups (Figure 2). The statistical analysis showed that the interaction of temperature and salinity did not have a significant effect on the growth of ephyrae (two-way ANOVA, p>0.05).

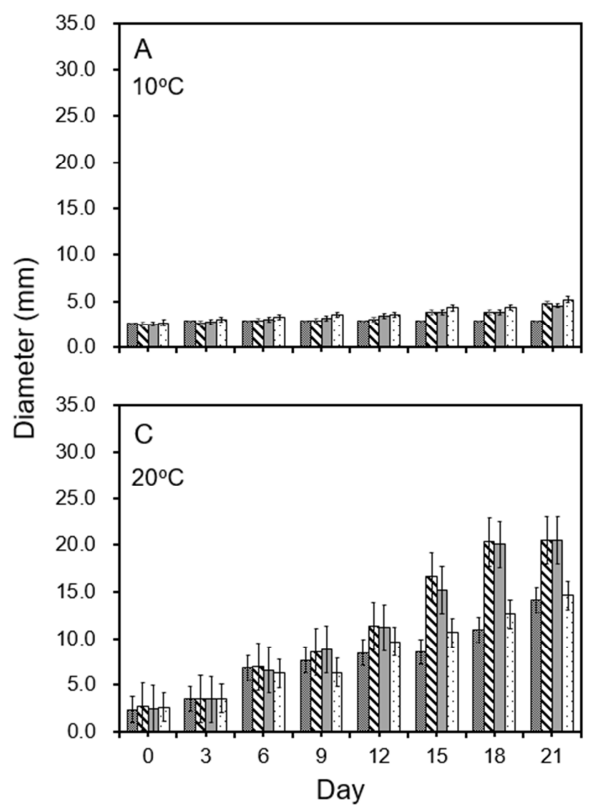

\subsection{Effect of Temperature and Salinity on the Rate of Pulsation in Ephyrae}

The mean pulsation rates in newly released ephyrae were 24.2 $\pm 6.4,39.1 \pm 3.8,52.5 \pm 4.9$, and $73.15 \pm 5.09$ beats individual ${ }^{-1}$ $\min ^{-1}$ at $10,15,20$, and $25^{\circ} \mathrm{C}$ in all salinities, respectively (Figure 3 ), and there was a significant difference between the temperature groups (one-way ANOVA, $\mathrm{p}<0.01$ ). As the ephyrae grew, the mean pulsation rate gradually decreased. The trend was highly pronounced at higher water temperatures. Over the experimental period of 21 days, temperature showed a significant effect on the pulsation rates of ephyrae (two-way ANOVA, $\mathrm{p}<0.01$ ); however, no significant effects were observed for the impact of salinity and its combined effect with temperature (two-way ANOVA, $\mathrm{p}>0.05$ ).

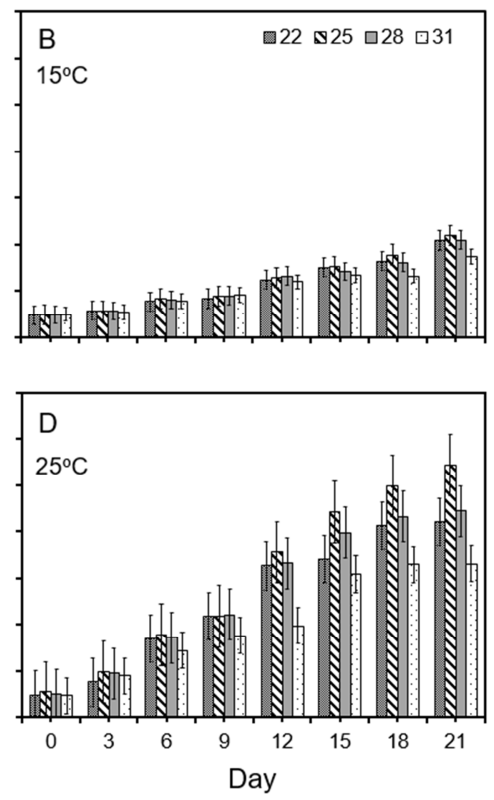

Figure 1. Means of body diameters increase of Aurelia coerulea ephyrae under 4 salinities at $10(A), 15(B), 20(C)$ and $25^{\circ} \mathrm{C}(D)$ during a 21-d experiment.
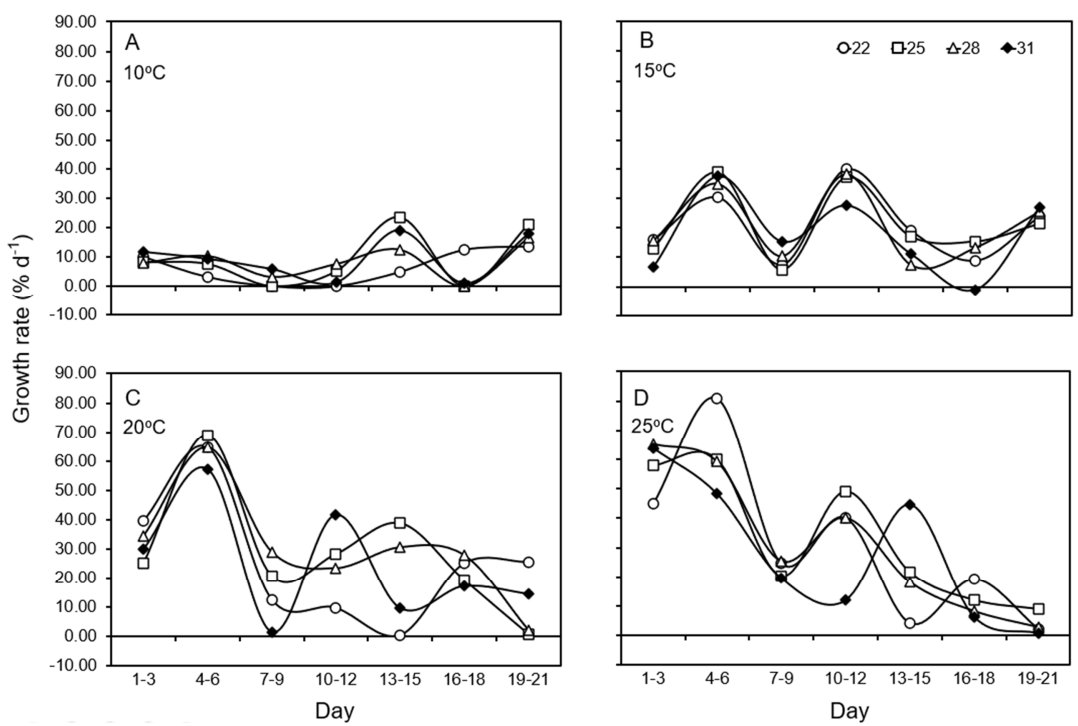

Figure 2. Change of growth rates of Aurelia coerulea ephyrae under 4 salinities at $10(\mathrm{~A}), 15(\mathrm{~B}), 20(\mathrm{C})$ and $25^{\circ} \mathrm{C}(\mathrm{D})$ during a 21-d experiment. 

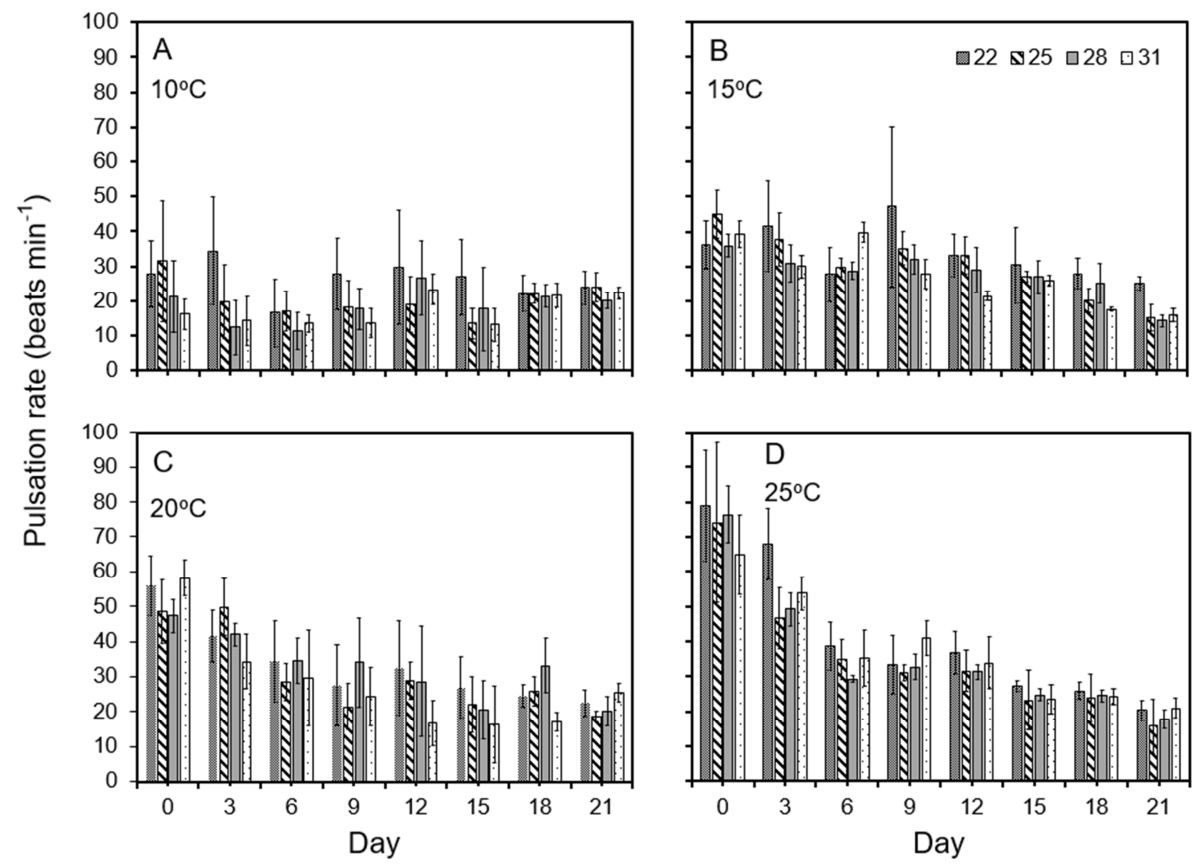

Figure 3. Change of pulsation rates of Aurelia coerulea ephyrae under 4 salinities at $10(A), 15(B), 20(C)$ and $25^{\circ} \mathrm{C}(D)$ during a 21-d experiment.

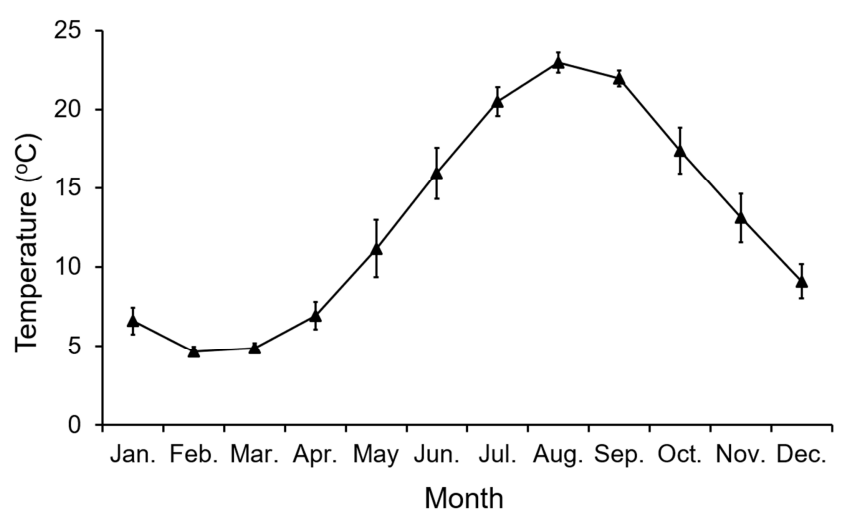

Figure 4. Annual sea surface water temperatures in Xinghai Bay, Dalian, northern Yellow Sea in 2017.

\section{Discussion}

\subsection{Effect of Temperature and Salinity on the Growth Rate of Ephyrae}

Unlike most previous studies on the growth of $A$. aurita ephyrae and medusae, which were restricted to several days $[14,15,20-22]$, our study was a long-term experiment that was conducted for 21 days, covering the entire development period from 2.5-mm ephyrae to young medusae with a maximum diameter of approximately $3 \mathrm{~cm}$. In our experiment, A. coerulea ephyrae were fed excess Artemia nauplii twice daily; this feeding strategy promoted the maximum growth rate in ephyrae, maximizing the differences between treatments. Most previous studies on the growth of ephyrae recorded the size of the ephyrae at the beginning and the end of the study. Our study measured the size of ephyrae and calculated the growth rate at 3-d intervals. Thus, our results have a significantly better statistical foundation than those of previous studies.

Growth rates of ephyrae of the genus Aurelia have been recorded in only two studies [14, 15]. Båmstedt et al. [14] demonstrated that $A$. aurita ephyrae exhibited a rapid growth rate (up to $70 \% \mathrm{~d}^{-1}$ ) initially, followed by reduction to 20 to $40 \% \mathrm{~d}^{-1}$ consistent with the results for the ephyrae of $A$. labiata [15]. The growth rates were higher during the first 7 days of the experiment, reaching $41.35 \% \mathrm{~d}^{-1}$, and then they decreased to $\sim 17.82 \% \mathrm{~d}^{-1}$ during days 7-14. In our study, the growth rate showed a similar trend. A. coerulea ephyrae had a rapid growth rate for the first 6 days; thereafter, the growth rate showed a general decreasing trend. This result is in accordance with previous studies. Moreover, the maximum growth rate recorded in our study was $81 \% \mathrm{~d}^{-1}$, which is higher than those in previous studies. However, here, food was provided ad libitum, similar to previous studies. In the natural environment, this range of food concentration $(>300$ prey $\mathrm{L}^{-1}$ ) is not generally found, and thus, these results could be situations with a high abundance of food.

The differences in the growth of $A$. coerulea ephyrae at different temperatures were observable and noticeable in this study. Although the average size of ephyrae was the same in all groups at the beginning of the experiment, we observed that the average diameter of ephyrae was five times higher at $25^{\circ} \mathrm{C}$ than at $10^{\circ} \mathrm{C}$ at the end of the 21 -day experiment. Ephyrae reared at different temperatures had different fates. For the first 12 days of the experiment, slow growth of ephyrae was observed at $10^{\circ} \mathrm{C}$ (Figure 2), followed by an increase between days 13-19, which may be attributed to the growth of larger guts and the subsequent ability to ingest an increased amount of food and energy to allocate to growth [15, 23]. It was observed that low temperatures led to a decrease in the feeding rates of $A$. aurita ephyrae. Ephyrae at $10^{\circ} \mathrm{C}$ did not appear to be active feeders, although Artemia nauplii were occasionally observed in their guts. Although the growth rate 
of ephyrae at $10^{\circ} \mathrm{C}$ was slow, as they increased their diameter from $2.5 \mathrm{~mm}$ to only $4.60 \mathrm{~mm}$, they grew well and did not exhibit any bell deformations or moribundity. Therefore, it appears that $A$. coerulea ephyrae in the field could survive at $10^{\circ} \mathrm{C}$ for a minimum of 21 days and then regrow if the temperature increased.

At 20 and $25^{\circ} \mathrm{C}$, ephyrae showed a higher growth rate for the first 6 days; however, at 7-8 $\mathrm{mm}$ size, several ephyrae everted their bells and were unable to swim or feed effectively, leading to a reduced bell diameter. This phenomenon was also described by Widmer [15]. However, in the current study, the deformation caused by bell eversion in ephyrae occurred at $15^{\circ} \mathrm{C}$, which was much lower than that reported by Widmer [15]. We attempted to mechanically restore their bells to a normal state, but some ephyrae could not recover. Widmer [15] concluded that the deformation was caused by heat stress. However, we do not fully agree with this conclusion since some of the ephyrae in the $15^{\circ} \mathrm{C}$ group also everted in their bells, although the number of deformed ephyrae was much lower than those in the 20 and $25^{\circ} \mathrm{C}$ groups. The mechanism of bell eversion in ephyrae remains unclear, and further studies are needed to clarify the cause of this phenomenon.

The optimum temperature for the growth of the genus Aurelia has been reported in many laboratory studies. For medusae, the optimum temperature for growth was reported to be $16.4^{\circ} \mathrm{C}$ (in $A$. aurita originally from Gullmarsfjorden, Sweden; [21]); for ephyrae, the optimum temperatures were reported to be $18^{\circ} \mathrm{C}$ (the $A$. aurita ephyrae origin is not recorded, but they are speculated to be from northern Europe; [14]) and $21^{\circ} \mathrm{C}$ (A. labiata ephyrae originally from Monterey Bay, US; [15]). In this study, the maximum growth rates of $A$. coerulea ephyrae (originally from the northern Yellow Sea, China) occurred at $25^{\circ} \mathrm{C}$, which is in contrast with previous studies. We consider that the differences in optimal growth temperatures are caused by long-term adaptation of genus Aurelia to their respective environments.

Salinity within the tested range had no significant effect on the growth of $A$. coerulea ephyrae. Ephyrae grew well under all salinity conditions, indicating that the salinity range of 22-31 PSU is suitable for the growth of $A$. aurita ephyrae. The maximum growth rates were recorded in the 25 and 28 PSU groups, indicating that ephyrae may prefer to live in estuarine coastal areas. The salinity range tested in this study corresponded to salinity conditions likely to be encountered by naturally occurring colonies in the northern Yellow Sea. The tolerance of ephyrae to a range of salinity regimes allows them to survive and grow under different salinity conditions and thus maximize the population size of adult medusae in marine environments.

Interactions of temperature and salinity did not significantly affect the growth of $A$. coerulea ephyrae. However, the deformation of ephyrae caused by bell eversion tended to appear in the high salinity groups. The number of deformed ephyrae was highest in the $20^{\circ} \mathrm{C}-31 \mathrm{PSU}$ and $25^{\circ} \mathrm{C}-31 \mathrm{PSU}$ groups; no ephyrae showed deformations in the $22 \mathrm{PSU}$ treatment groups. This result suggests that temperature and salinity might have additive effects on the deformation of ephyrae.

\subsection{Effects of Temperature and Salinity on the Pulsation of Ephyrae}

A. coerulea detects their prey physically and do not possess the ability to detect their prey remotely. Thus, there is a strong correlation between swimming and feeding. Here, the maximum pulsation rate was found to be 78.9 beats $\mathrm{min}^{-1}$. The maximum swimming speed of $A$. coerulea ephyrae was estimated to be $14.2 \mathrm{~cm} \mathrm{~min}^{-1}$ based on $1.88 \mathrm{~mm}$ movement/pulsation [24]. This swimming speed was much slower than the escape speed of many zooplankton [24]. Studies have observed a continuous swimming pattern in $A$. aurita ephyrae since they are cruising predators [24]. Based on this pattern, A. coerulea ephyrae mainly capture slow-moving planktonic prey in the field, including immobile prey, such as fish eggs, and slow-moving prey, such as veliger larvae, barnacle nauplii, and hydromedusae. Copepod nauplii (escape speed: $120 \mathrm{~cm} \mathrm{~min}^{-1}$ ) would not be expected to be major prey items, and copepodites and adult copepods that characteristically escape at $>300 \mathrm{~cm} \mathrm{~min}^{-1}$ are not generally consumed by $A$. coerulea ephyrae.

Temperature significantly influenced the pulsation rates of $A$. coerulea ephyrae. The pulsation rates increased with increasing temperatures from $10-25^{\circ} \mathrm{C}$. This result is consistent with previous studies. However, as ephyrae developed into medusae, the pulsation rate decreased. This may be because as their body volume increases, their clearance rate, prey encounter rate, and prey capture success rate correspondingly increase. The effect of temperature on the pulsation rate of $A$. coerulea ephyrae also affected growth. The temperature-dependent growth observed in this study could be related to the irregular predation rate caused by temperature-dependent activity as $A$. coerulea are known to capture prey resulting from the swim propulsion activity-driven currents [21, 25].

Here, we observed that under all salinity conditions, ephyrae swam actively, and showed an insignificant difference in their rates of pulsation among the salinities tested. Dillion [18] showed that acute changes in salinity significantly increased pulsation rates. This difference could be attributed to the fact that the ephyrae in this study had a longer adaptation time compared with previous studies. At 22 to 31 PSU salinity, which is experienced by $A$. aurita ephyrae in the wild, ephyrae can swim actively to escape from predators and seek food.

\subsection{A. Coerulea Ephyrae in the Wild}

A. aurita is a eurythermal and euryhaline species that is distributed in water within a temperature range of $0-32^{\circ} \mathrm{C}$ and a salinity range of $<10$ to 38 PSU [26]. The population dynamics of $A$. coerulea in Jiaozhou Bay, northern Yellow Sea has been reported by Wang and Sun [16]. They found that $A$. coerulea ephyrae occurred from May to June when the temperature ranged from 12 to $18^{\circ} \mathrm{C}$. Moreover, Wang and $\mathrm{Li}$ [17] conducted a laboratory experiment and found that the 
strobilation of $A$. coerulea occurred between $8-17^{\circ} \mathrm{C}$. According to these results, the strobilation of $A$. coerulea in the Dalian area, northern Yellow sea, would be occurred between late April and late June when the in situ water temperature is between $8-17^{\circ} \mathrm{C}$. Furthermore, previous studies in other regions have also reported that the beginning of the growth of $A$. aurita ephyrae in spring is determined by the water temperature [27]. The growth of $A$. aurita ephyrae in temperate areas remains stagnant in winter and early spring and rapidly increases in summer [26]. If we apply the results of this experiment to speculate the growth of $A$. coerulea ephyrae in the northern Yellow Sea, the rapid growth of $A$. coerulea is expected in mid-May when the temperature of the northern Yellow Sea is higher than $10^{\circ} \mathrm{C}$ (Figure 4). The results of this experiment also indicate that blooms of $A$. coerulea are more likely to occur in years when the water temperature is warm in spring.

\section{Conclusions}

The growth and pulsation of Aurelia coerulea ephyrae were examined at four temperatures and four salinities in laboratory experiments over the $21-\mathrm{d}$ period. Temperature significantly affected the growth rates of ephyrae. Feeding of ephyrae was more active at higher temperatures, and digestion times decreased with an increase in temperature. The average diameters of ephyrae were the same at the beginning of the experiment. At the end of the 21-d experiment, the average diameters of ephyrae were 4.60, 10.18, 17.48, and $21.75 \mathrm{~mm}$ at $10,15,20$, and $25^{\circ} \mathrm{C}$, respectively. The growth rates showed a cyclical trend. Salinity and its interaction with temperature were not significantly affected the growth rates. The highest rate of pulsation for $A$. coerulea ephyrae was found to 78.9 beats $\min ^{-1}$, with a corresponding maximum swimming velocity of $14.2 \mathrm{~cm} \mathrm{~min}^{-1}$. Since this swimming speed was much lower than the speed of common zooplanktons, such as copepods, it implied that ephyrae could only capture slow-moving prey. There was a significant impact of temperature on the pulsation rates, which generally decreased as ephyrae grown to medusae. Salinity and its interaction with temperature did not have a significant effect on the pulsation of ephyrae. We conclude that A. coerulea ephyrae in the northern Yellow Sea may occur between May and late June, and the warm spring can cause $A$. coerulea blooms in that year.

\section{Acknowledgements}

This research was funded by the Natural Science Foundation of Guangxi Province, China (2016GXNSFCA380015), Science and Technology Major Project of Guangxi (AA17202020), Xiangsihu Young Scholars Innovative Research Team of Guangxi University for Nationalities (2018RSCXSHQN02, 201706) and the Training Program for A Thousand Young and Middle-aged Backbone Teachers in Colleges and Universities in Guangxi.

\section{References}

[1] Pereira, R., Teodósio, M. A. and Garrido, S. (2014) An Experimental Study of Aurelia aurita Feeding Behaviour: Inference of the Potential Predation Impact on a Temperate Estuarine Nursery Area. Estuarine, Estuarine Coastal Shelf Science, 146, 102-110.

[2] Purcell, J. E. and Arai, M. N. (2001) Interactions of Pelagic Cnidarians and Ctenophores with Fish: A Review. Hydrobiologia, 451, 27-44.

[3] Lynam, C. P., Gibbons, M. J., Axelsen, B. E., Sparks, C. A. J., Coetzee, J., Heywood, Benjamin G. and Brierley, A. S. (2006) Jellyfish Overtake Fish in a Heavily Fished Ecosystem. Current Biology, 16, 1976.

[4] Richardson, A. J., Bakun, A., Hays, G. C. and Gibbons, M. J. (2009) The Jellyfish Joyride: Causes, Consequences and Management Responses to a More Gelatinous Future. Trends in Ecology \& Evolution, 24, 312-322.

[5] Uye, S.-i. (2011) Human Forcing of the Copepod-fish-jellyfish Triangular Trophic Relationship. Hydrobiologia, 666, 71-83.

[6] Dong, Z. Blooms of the Moon Jellyfish Aurelia: Causes, Consequences and Controls. in Sheppard, C. (Eds), World Seas An Environmental Evaluation. Vol. III. Ecological Issues and Environmental Impacts. Elsevier Ltd., London, 2019, pp. 163171.

[7] Dong, Z., Liu, D. and Keesing, J. K. (2010) Jellyfish Blooms in China: Dominant Species, Causes and Consequences. Marine Pollution Bullen, 60, 954-963.

[8] Purcell, J. E., Uye, S. I. and Lo, W. T. (2007) Anthropogenic Causes of Jellyfish Blooms and Their Direct Consequences for Humans: A Review. Marine Ecology Progress Series, 350, 153-174.

[9] Dong, Z., Liu, D. and Keesing, J. K. Population Changes of Rhopilema esculentum with Special Reference to Its Fishery and Stock Enhancement, in: Pitt, K. A., Lucas, C. H. (Eds.), Jellyfish blooms. Springer Dordrecht, New York London, 2014, pp. 186-207.

[10] Su, L. and Wang, Y. (2007) Exploring the Mystery of Moon Jellyfish Bloom at Yantai. Beijing Sci-Tech-Report, 37, 16-17.

[11] Zheng, F. Y., Chen, S. Q. and Jia, N. I. (2010) Biological Characteristics of Moon Jellyfish (Aurelia aurita Linnaeus, 1758) and Its Bloom. Advances in Marine Science, 28, 126-132.

[12] Purcell, J. (2012) Jellyfish and Ctenophore Blooms Coincide with Human Proliferations and Environmental Perturbations. Annual review of marine science, 4, 209-35.

[13] Duarte, C. M., Pitt, K. A., Lucas, C. H., Purcell, J. E., Uye, S.-i., Robinson, K., Brotz, L., Decker, M. B., Sutherland, K. R., Malej, A., Madin, L., Mianzan, H., Gili, J.-M., Fuentes, V., Atienza, D., Pagés, F., Breitburg, D., Malek, J., Graham, W. M. and Condon, R. H. (2013) Is Global Ocean Sprawl a Cause of Jellyfish Blooms? Frontiers in Ecology and the Environment, 11 (2), 91-97.

[14] Båmstedt, U., Lane, J. and Martinussen, M. B. (1999) Bioenergetics of Ephyra Larvae of the Scyphozoan Jellyfish Aurelia aurita in Relation to Temperature and Salinity. Marine Biology, 135, 89-98. 
[15] Widmer, C. L. (2005) Effects of Temperature on Growth of North-East Pacific Moon Jellyfish Ephyrae, Aurelia labiata (Cnidaria: Scyphozoa). Journal of the Marine Biological Association of the United Kingdom, 85, 569-573.

[16] Wang, Y.-T. and Sun, S. (2015) Population Dynamics of Aurelia sp. 1 Ephyrae and Medusae in Jiaozhou Bay, China. Hydrobiologia, 754, 147-155.

[17] Wang, N. and Li, C. (2015) The Effect of Temperature and Food Supply on the Growth and Ontogeny of Aurelia sp. 1 Ephyrae. Hydrobiologia, 754, 157-167.

[18] Dillon, T. (1977) Effects of Acute Changes in Temperature and Salinity on Pulsation Rates in Ephyrae of the Scyphozoan Aurelia aurita. Marine Biology, 42, 31-35.

[19] Mangum, C., Oakes, M. and Shick, J. (1972) Rate-temperature Responses in Scyphozoan Medusae and Polyps. Marine Biology, 15, 298-303.

[20] Hernroth, L. and Gröndahl, F. (1983) On the Biology of Aurelia aurita (L.) 1. Release and Growth of Aurelia aurita (L.) Ephyrae in the Gullmar Fjord, Western Sweden, 1982-83. Ophelia, 22, (2), 189-199.
[21] Hansson, L. J. (1997) Effect of Temperature on Growth Rate of Aurelia aurita (Cnidaria, Scyphozoa) from Gullmarsfjorden, Sweden. Marine Ecology Progress Series, 161, 145-153.

[22] Ishii, H. and Bamstedt, U. (1998) Food Regulation of Growth and Maturation in a Natural Population of Aurelia aurita (L.). Journal of Plankton Research, 20, 805-816.

[23] Graham, W. M. and Kroutil, R. M. (2001) Size-based Prey Selectivity and Dietary Shifts in the Jellyfish, Aurelia aurita. Journal of Plankton Research, 23, 67-74.

[24] Sullivan, B. K., Suchman, C. L. and Costello, J. H. (1997) Mechanics of Prey Selection by Ephyrae of the Scyphomedusa Aurelia aurita. Marine Biology, 130, 213-222.

[25] Costello, J. H. and Colin, S. P. (1994) Morphology, Fluid Motion and Predation by the Scyphomedusa Aurelia aurita. Marine Biology, 121, 327-334.

[26] Lucas, C. H. (2001) Reproduction and Life History Strategies of the Common Jellyfish, Aurelia aurita, in Relation to Its Ambient Environment. Hydrobiologia, 451, 229-246.

[27] Möller, H. (1980) Population Dynamics of Aurelia aurita Medusae in Kiel Bight, Germany (FRG). Marine Biology, 60, 123-128. 